\title{
Clinical features and prognosis of infant acute lymphoblastic leukemia in China: A single-center retrospective analysis
}

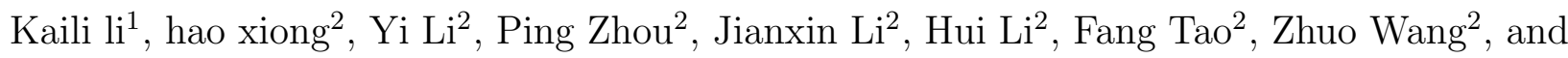 \\ Zhi Chen ${ }^{2}$ \\ ${ }^{1}$ Wuhan Children's Hospital (Wuhan Maternal and Child Healthcare Hospital), Tongji \\ Medical College, Huazhong University of Science \& Technology \\ ${ }^{2}$ Wuhan Children's Hospital (Wuhan Maternal and Child Healthcare Hospital) Tongji \\ Medical College, Huazhong University of Science \& Technology
}

May 29, 2020

\begin{abstract}
Background: In this retrospective analysis, we investigate the clinical features and prognosis of 23 infant patients $(<1$ year of age) diagnosed with acute lymphoblastic leukemia (ALL). Methods: We used clinical data of 23 children diagnosed with infant ALL at the Department of Pediatric Hematology \& Oncology, Wuhan Children's Hospital, between 1st January 2014 and 30th September 2019. EFS and OS rate curves were computed using the Kaplan-Meier estimator. The impact of prognostic factors on outcome was analyzed using the Cox model. Results: The median WBC was $46.14(6.46-513) \times 10^{9} / \mathrm{L}$ at initial diagnosis. All 21 patients immunophenotyped by flow cytometry had B-lineage ALL. KMT2A-rearrangement was identified in $72.2 \%(13 / 18)$ patients. Mutation screening for 13 patients indicated 4 patients with KRAS mutations, 4 with TTN mutations, 2 with NOTCH1 mutations, 2 with PTPN11 mutations and 2 with NRAS mutations. Of 12 patients who received chemotherapy, complete remission was achieved for $83.3 \%$ patients after one course of remission induction. A total of 3 patients underwent related haploidentical allogeneic hematopoietic stem cell transplantation. The expected 2-year overall survival (OS) rate was $55.6+-15.2 \%$ and the expected event free survival rate (EFS) was $44.4+-15.7 \%$. Univariate analysis revealed WBC $>100$ x $10^{9} / \mathrm{L}$ at initial diagnosis as a risk factor for poor OS and EFS. Conclusion: Treatment of infant ALL with the standard childhood ALL regimen achieved an OS rate similar to patients with high-risk ALL, and WBC at initial diagnosis may be an important prognostic indicator.
\end{abstract}

\section{Hosted file}

Clinical features and prognosis of infant acute lymphoblastic leukemia in China- A single-center retros available at https://authorea.com/users/327659/articles/455258-clinical-features-andprognosis-of-infant-acute-lymphoblastic-leukemia-in-china-a-single-center-retrospectiveanalysis 

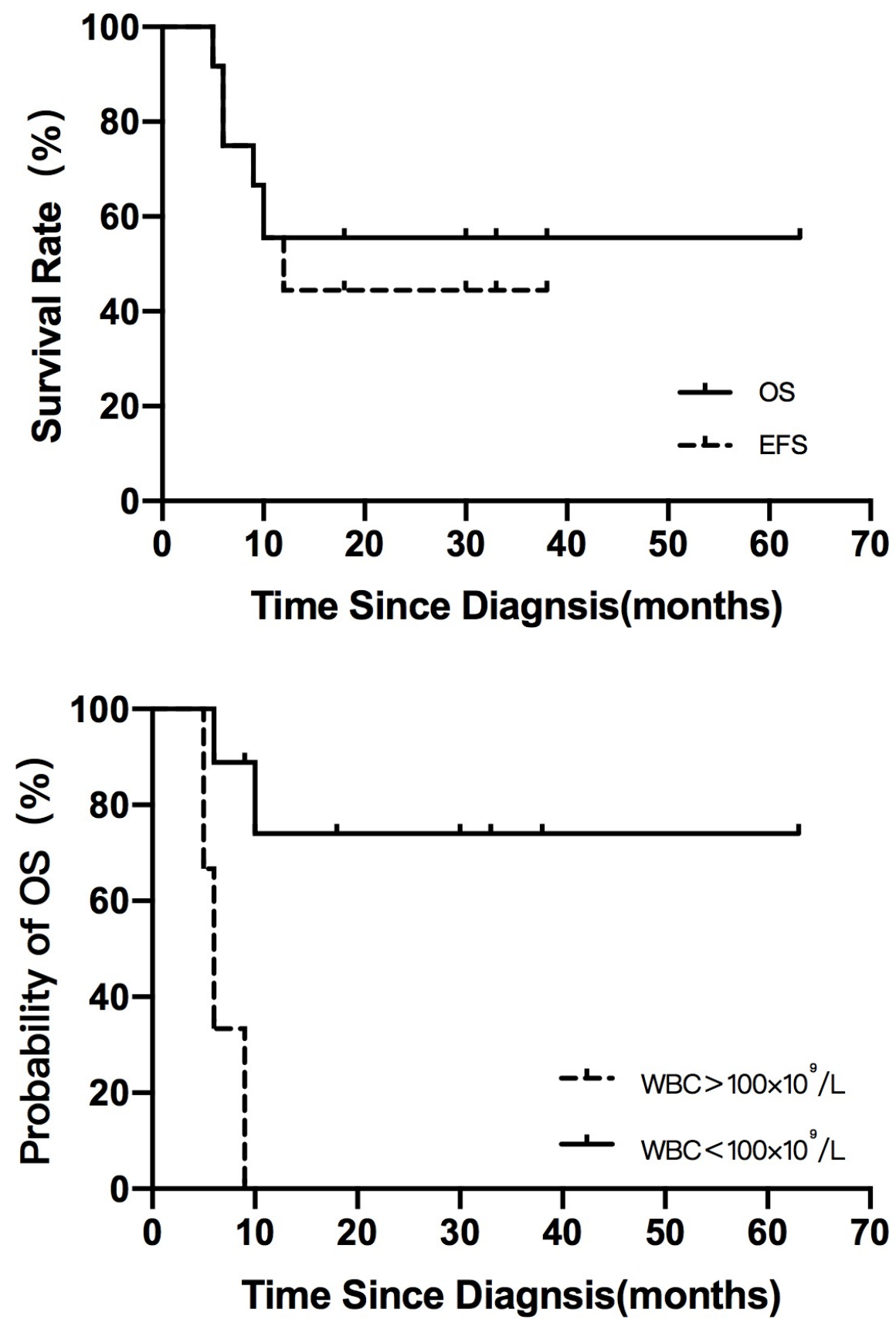


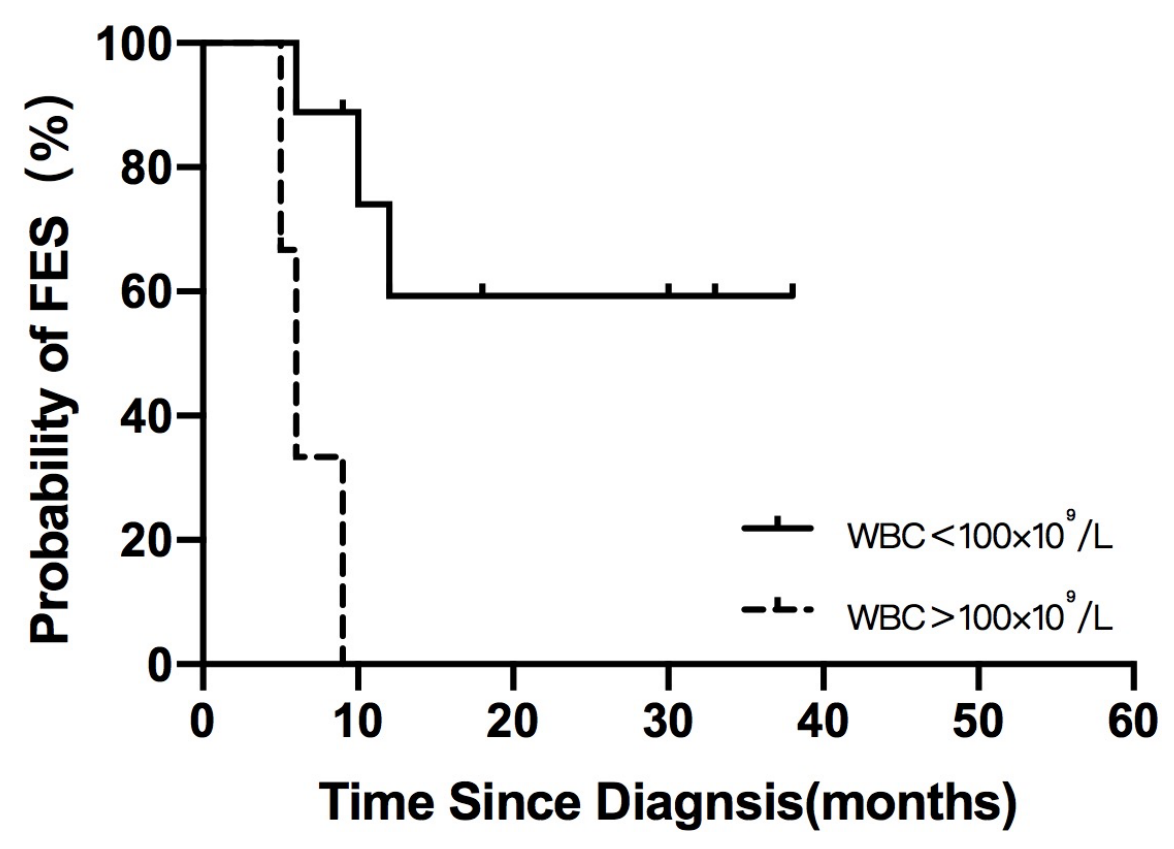

Hosted file

Table 1. Clinical and molecular features of Patients with infant ALL .docx available https://authorea.com/users/327659/articles/455258-clinical-features-and-prognosis-ofinfant-acute-lymphoblastic-leukemia-in-china-a-single-center-retrospective-analysis

Hosted file

Table 2.Summary of results for infant ALL in recent clinical trials.docx available at https://authorea.com/users/327659/articles/455258-clinical-features-and-prognosis-ofinfant-acute-lymphoblastic-leukemia-in-china-a-single-center-retrospective-analysis 